\title{
Unravelling the Keto-Enol Tautomer Dependent Photochemistry and Degradation Pathways of the Protonated UVA Filter Avobenzone
}

\author{
Jacob A. Berenbeim, Natalie G. K. Wong, Martin C. R. Cockett, Giel Berden, Jos Oomens, \\ Anouk M. Rijs, and Caroline E. H. Dessent*
}

Cite This: J. Phys. Chem. A 2020, 124, 2919-2930

Read Online

ACCESS | Lلll Metrics \& More | 回 Article Recommendations

Supporting Information

ABSTRACT: Avobenzone (AB) is a widely used UVA filter known to undergo irreversible photodegradation. Here, we investigate the detailed pathways by which $\mathrm{AB}$ photodegrades by applying UV laser-interfaced mass spectrometry to protonated $\mathrm{AB}$ ions. Gas-phase infrared multiple-photon dissociation (IRMPD) spectra obtained with the free electron laser for infrared experiments, FELIX, $\left(600-1800 \mathrm{~cm}^{-1}\right)$ are also presented to confirm the geometric structures. The UV gas-phase absorption spectrum $(2.5-5 \mathrm{eV})$ of protonated $\mathrm{AB}$ contains bands that correspond to selective excitation of either the enol or diketo forms, allowing us to probe the resulting, tautomer-dependent photochemistry. Numerous photofragments

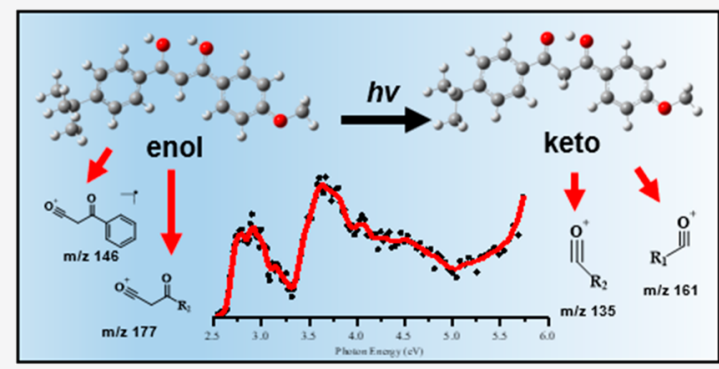
(i.e., photodegradants) are directly identified for the first time, with $\mathrm{m} / z 135$

and 161 dominating, and $m / z 146$ and 177 also appearing prominently. Analysis of the production spectra of these photofragments reveals that that strong enol to keto photoisomerism is occurring, and that protonation significantly disrupts the stability of the enol (UVA active) tautomer. Close comparison of fragment ion yields with the TD-DFT-calculated absorption spectra give detailed information on the location and identity of the dissociative excited state surfaces, and thus provide new insight into the photodegradation pathways of avobenzone, and photoisomerization of the wider class of $\beta$-diketone containing molecules.

\section{INTRODUCTION}

So that the skin can be protected against radiation damage linked to sunlight exposure, considerable effort has been put into the development of effective sunscreens. ${ }^{1-4}$ Over recent years, a number of advanced laser spectroscopic studies have been conducted on sunscreen molecules under highly controlled conditions, with the aim of improving our fundamental knowledge of the mechanisms by which molecular sunscreens function. ${ }^{1,5-13}$ Such measurements aim to provide fundamental insights into the properties of the sunscreen molecule free from the complications of the complex environment of a real sunscreen lotion. One group of experiments has focused on "isolated" gas-phase sunscreen molecules to provide information on how UV light absorption varies as a function of molecular structure. ${ }^{11,12,14-16}$ A second group of studies have used transient absorption spectroscopy to probe relaxation dynamics of two-component mixtures of a single organic sunscreen molecule in a single solvent. ${ }^{1,6-8,10}$ Experiments are typically complemented by high-level quantum chemical calculations, ${ }^{17-22}$ which then provide important insights into the mechanism by which the sunscreen molecule operates.

Avobenzone (AB: 4-tert-butyl-4'-methoxydibenzoylmethane; BD-DBM or Parsol 1789) is a widely used UVA filter which is known to suffer from irreversible UV-driven photodegradation. ${ }^{1,23,24} \mathrm{AB}$ is a dibenzoylmethane derivative and a member of a family of molecules known to take multiple isomerization pathways following UV excitation. ${ }^{25-30}$ Photoexcitation of $A B$ is believed to lead to nonadiabatic population of high-lying $S_{0}$ vibrational levels, which can lead to isomerization to a less photostable form. ${ }^{31}$ Previous photolysis experiments performed in hexane have shown that this photodegradation of $\mathrm{AB}$ occurs by a Norrish type 1 mechanism. ${ }^{32,33}$ (The key tautomeric forms of $\mathrm{AB}$ involved in this photoisomerization are illustrated in Scheme 1.) In the ground state, $\mathrm{AB}$ is mostly found in its chelated enol (CE) form due to the stabilizing intramolecular hydrogen bond, although the diketo (DK) form is also typically present, with the relative tautomeric ratios being strongly solvent dependent. The CE form is the active UVA blocker $\left(\lambda_{\max }=355 \mathrm{~nm}\right)$, with photoisomerization leading to nonchelate forms, which gradually populate the DK form. The DK tautomer absorbs

Received: February 14, 2020

Revised: $\quad$ March 25, 2020

Published: March 25, 2020 
Scheme 1. Schematic Diagram Illustrating the UVA Active Chelated-Enol (CE) and UVB Active Diketo (DK)

Tautomer of Avobenzone. Irradiation of the DK Tautomer Causes Photoinitiated $\alpha$-Cleavage

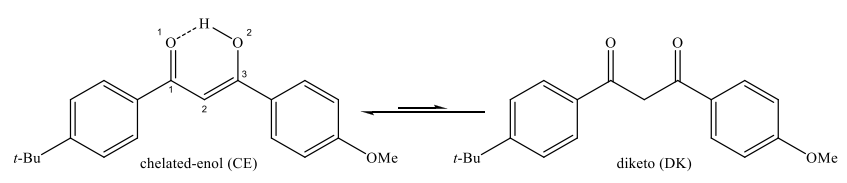

at higher UV energies $\left(\lambda_{\max }=265 \mathrm{~nm}\right)$ and has been shown to be responsible for formation of a reactive triplet. Indeed, the instability of the diketo form is well established. ${ }^{32,34-36}$ Wang et al., for example, demonstrated that $\mathrm{AB}$ photodegrades (in the UVA) more quickly as a function of chlorine substitution at the $\alpha$-carbon (C2) since this promotes the diketo form. ${ }^{37}$

A considerable number of studies have been performed to explore how $\mathrm{AB}$ tautomerization, and hence photostability, is affected by the solvent. ${ }^{38-40}$ These studies prompt questions of whether other local environmental factors can influence the extent of tautomerization. In this work, we directly address one such issue, namely the potential effect of acid conditions on the photochemistry of $\mathrm{AB}$ by directly studying the protonated form of $\mathrm{AB}$, i.e. $\mathrm{AB} \cdot \mathrm{H}^{+}$, as an isolated system in the gas phase. We use laser-interfaced mass spectrometry (LIMS) to select ions that are then subjected to wavelength-dependent laser photodissociation, allowing us to measure the gas-phase absorption spectrum. ${ }^{41,42}$ LIMS has recently been shown to be a useful tool for studying isomeric systems. ${ }^{43-47}$ Applying LIMS to $\mathrm{AB} \cdot \mathrm{H}^{+}$allows us to selectively investigate the photochemistry of both enol and keto tautomers, and to probe the extent to which tautomerization occurs, away from any influences of the bulk-phase environment. Importantly, our experiments also allow us to measure the photodegradants of the individual $\mathrm{AB} \cdot \mathrm{H}^{+}$tautomers. To complement the $\mathrm{UV}$ photochemistry, we present infrared multiple-photon dissociation (IRMPD) spectroscopy of $\mathrm{AB} \cdot \mathrm{H}^{+}$to confirm which tautomers are present.

Fundamental studies of the effect of $\mathrm{pH}$ on sunscreen molecules to date are sparse. ${ }^{5,41,48,49}$ Recent measurements from our group have highlighted the impact of protonation and deprotonation on oxybenzone, in terms of the nature and wavelength dependence of its UV photofragmentation pathways. ${ }^{41}$ A separate study of deprotonated 2-phenylbenzimidazole-5-sulfonic acid provided direct evidence for the production of free radical photoproducts following UVA excitation. ${ }^{42}$ We note, however, that there is broad interest in the effect of $\mathrm{pH}$ in the field of environmental chemistry and degradation of man-made pollutants present in surface water, $^{50-56}$ so that further work assessing the effect of $\mathrm{pH}$ on individual sunscreens is highly desirable.

\section{METHODS}

Gas-phase UV photodissociation experiments were conducted in an AmaZon SL dual funnel electrospray ionization quadrupole ion trap (ESI-QIT) mass spectrometer (Bruker Daltonics Inc., Billerica, MA, USA), which was modified to allow LIMS. ${ }^{41,43,57}$ Avobenzone (AB) was purchased from Sigma-Aldrich (St. Louis, MO, USA) and HPLC-grade EtOH was purchased from Fisher Scientific, Inc. (Pittsburgh, PA, USA), both used as received. Solutions of $\mathrm{AB}\left(1 \times 10^{-4} \mathrm{~mol}\right.$ $\mathrm{dm}^{-3}$ ) in EtOH were electrosprayed using typical instrumental parameters (nebulizing gas pressure of $10.0 \mathrm{psi}$; injection rate of $0.33 \mathrm{~mL} / \mathrm{h}$; drying gas flow rate of $8.0 \mathrm{~L} / \mathrm{min}$ ), and run in positive ion mode at a capillary temperature of $100{ }^{\circ} \mathrm{C}$.

$\mathrm{AB} \cdot \mathrm{H}^{+}$was mass selected and isolated in the ion-trap prior to laser irradiation. UV-vis photons were produced by a $10 \mathrm{~Hz}$ Nd:YAG (Surelite, Amplitude Laser Group, San Jose, CA, USA) pumped OPO (Horizon, Amplitude Laser Group) laser, giving $\sim 0.3 \mathrm{~mJ}$ across the range $400-216 \mathrm{~nm}(3.10-5.80 \mathrm{eV})$. A $2 \mathrm{~nm}$ laser step size was used to record the photodepletion and photofragment spectra of the $\mathrm{AB} \cdot \mathrm{H}^{+}$parent ion. To check for single-photon conditions, the laser power dependence on signal was determined as described previously. ${ }^{42}$

Photofragmentation experiments were conducted with an ion accumulation time of $20 \mathrm{~ms}$ and a fragmentation time of $100 \mathrm{~ms}$, thereby ensuring that each mass-selected ion packet interacted with one laser pulse, minimizing the likelihood of multiphoton events. When fluorescence is negligible, ${ }^{58}$ the UV excited gaseous ion will fragment upon excited state relaxation, yielding an action absorption spectrum by photodepletion (PD). ${ }^{59,59,60} \mathrm{PD}$ was measured as a function of the scanned wavelength, with the photofragment production (PF) also recorded simultaneously at each wavelength, both of which according to

$$
\begin{aligned}
& \text { photodepletion intensity }=\frac{\ln \left(\frac{\mathrm{Int}_{\mathrm{OFF}}}{\mathrm{Int}_{\mathrm{ON}}}\right)}{\lambda \times P} \\
& \text { photofragmentation intensity }=\frac{\left(\frac{\text { Int }_{\mathrm{FRAG}}}{\text { Int }_{\mathrm{OFF}}}\right)}{\lambda \times P}
\end{aligned}
$$

where Int $_{\mathrm{OFF}}$ and $\mathrm{Int}_{\mathrm{ON}}$ are the peak intensities with laser off and on respectively; Int $_{\mathrm{FRAG}}$ is the selected fragment intensity with the laser on; $\lambda$ is the excitation wavelength $(\mathrm{nm})$; and $P$ is the tunable laser pulse energy $(\mathrm{mJ})$. The photodepletion intensities were taken from an average of three runs at each wavelength of the ranges studied. We note that fragment ions with $m / z<50$ are not detectable in our mass spectrometer because of the low-mass cutoff of the quadrupole ion trap. The UV photodepletion (absorption) spectra of the major $A B$ photofragments produced upon the photoexcitation of $\mathrm{AB} \cdot \mathrm{H}^{+}$ were also recorded using $\mathrm{MS}^{\mathrm{n}}$ scheme and mass-isolation feature available on the trapControl version 7.2 (Bruker Daltonics Inc.) software.

IR experiments were performed in a modified commercial quadrupole ion-trap mass spectrometer (Bruker, AmaZon Speed ETD). ${ }^{61,62}$ Ions were generated in an Apollo ESI source. Solutions of $\mathrm{AB} \cdot \mathrm{H}^{+}\left(1 \times 10^{-6} \mathrm{~mol} \mathrm{dm}{ }^{-3}\right)$ in $\mathrm{MeOH}$ were introduced at $180 \mu \mathrm{L} / \mathrm{h}$ flow rates, electrosprayed, and transferred into the trap. The ions of interest were massselected and fragmented by IRMPD. IR spectra in the 700$1800 \mathrm{~cm}^{-1}$ region were recorded using the FELIX infrared free electron laser. ${ }^{63}$ FELIX was set to produce IR radiation in the form of 5-10 $\mu$ s macropulses of $80-120 \mathrm{~mJ}$ per pulse at a 10 $\mathrm{Hz}$ repetition rate and with a bandwidth of $\sim 0.4 \%$ of the center frequency. The mass-selected ions were irradiated with one macropulse. Resonant absorption of IR radiation leads to an increase of the internal energy of an ion mediated by intramolecular vibrational redistribution (IVR), which eventually leads to unimolecular dissociation. ${ }^{64}$ After irradiation, a mass spectrum of the resulting ions in the trap is recorded. At each IR frequency point, six mass spectra were averaged. The dissociation was calculated from the mass spectra by relating 
the precursor ion and fragment ion intensities (eq 3) and plotted as a function of IR frequency. ${ }^{65}$

$$
\operatorname{IRMPD}=-\ln \frac{\text { Int }_{\text {PRECURSOR }}}{\left(\sum \text { Int }_{\text {PRECURSOR }}+\sum \text { Int }_{\text {FRAG }}\right)}
$$

The IRMPD intensity was linearly corrected for frequencydependent laser pulse energy. Spectra were also recorded at two levels of laser-pulse energy attenuation (factors of 2.00 and 3.16) to prevent excessive depletion of the precursor ions (saturation) and minimize formation of low $\mathrm{m} / z$ fragment ions which may be undetected in the ion trap and which would result in underestimated IRMPD intensities. ${ }^{65}$

Calculations were performed using density functional theory in Gaussian 09. ${ }^{66}$ All reported structures correspond to true minima, as confirmed by frequency calculations. Conformational molecular dynamics searches implemented by Schrodinger's MacroModel were conducted with mixed Monte Carlo torsional and low-mode sampling to generate possible conformers which were rapidly energy gradient minimized with the OPLS3e force field. ${ }^{67}$ Unique structures (RMSD $0.4 \AA$, $<100 \mathrm{~kJ} / \mathrm{mol}$ ) were then energy minimized at the $\omega$ B97X-D/ def2-SVP and M06-2X/def2-SVP levels of theory. An implicit solvent model was used to calculate the relative energies of conformers upon solvation. Frequency calculations at the B3LYP/def2-TZVPP level were performed to test that optimized structures are true minima and were used to interpret the IRMPD spectra. ${ }^{68}$

\section{RESULTS}

3.1. Quantum Chemical Calculations of Gas-Phase and Solution-Phase $\mathrm{AB} \cdot \mathrm{H}+$. Scheme 2 illustrates the key tautomeric structures of $\mathrm{AB} \cdot \mathrm{H}^{+}$. The atomic numbering system previously used by Kojic et al. is also followed here. ${ }^{27}$ The carbonyl group is the primary protonation site, although a natural population analysis of the low-energy structures indicates that the excess charge is delocalized (section S1). A conformational molecular dynamics search was conducted on $\mathrm{AB} \cdot \mathrm{H}^{+}$, with the proton located on either the $\mathrm{O} 1$ or $\mathrm{O} 2$ site, followed by DFT optimization. Table 1 displays the tautomer relative energies, in the gas-phase and solution (rotamers are omitted from Table 1 as their electronic spectra are expected to be identical at our experimental resolution). The results presented in Table 1 suggest that solvation has little effect on the relative tautomer energies. We note that for the $\mathbf{K b}$ structure, it was challenging to identify the minimum, which was only observed in the presence of solvent at the $\omega$ B97X-D level of theory. The calculated relative energies for the various $\mathrm{AB} \cdot \mathrm{H}^{+}$tautomers lead us to predict that the $\mathbf{K a}$ isomer will dominate, both in the gas phase and in ethanol solution, with the Ea isomer also being present at a much reduced but still significant level.

The lowest-energy isomers, $\mathbf{K a}$ and $\mathbf{K b}$, are planar across the aromatic and diketone moieties. Suffixes $\mathbf{a}$ and $\mathbf{b}$ identify tautomer protonation sites as $\mathrm{O} 2$ and $\mathrm{O} 1$, respectively, and this nomenclature is applied to the enol-like structures as well. The Ea structure represents the protonated enol form of $\mathrm{AB} \cdot \mathrm{H}^{+}$, which is nonplanar, with the $\mathrm{O} 1 \mathrm{H} 1$ bond $\left(\mathrm{H} 1 / \mathrm{O} 1 / \mathrm{C} 1 / \mathrm{R}_{1} 1\right)$ directed $+10^{\circ}$ out-of-plane and the $\mathrm{R}_{1}$-arene by $-30^{\circ}(\mathrm{O} 1 /$ $\left.\mathrm{C} 1 / \mathrm{R}_{1} 1 / \mathrm{R}_{1} 2\right)$. The $\mathbf{E b}$ structure is similarly nonplanar with the $\mathrm{O} 2 \mathrm{H} 2$ bond $\left(\mathrm{H} 2 / \mathrm{O} 2 / \mathrm{C} 3 / \mathrm{R}_{2} 1\right)$ positioned $+12^{\circ}$ and the $\mathrm{R}_{2}$ arene by $-26^{\circ}\left(\mathrm{O} 2 / \mathrm{C} 3 / \mathrm{R}_{2} 1 / \mathrm{R}_{2} 2\right)$. The $\mathrm{Ka}$ and Ea tautomer energies vary significantly with different functionals, with
Scheme 2. Schematic Diagram of the Key Tautomeric Structures of $\mathrm{AB} \cdot \mathrm{H}^{+}$with Atom and Rotation Coordinate Labels. The Ka Ketone and Ea Enol Tautomers Are Protonated at the $\mathrm{O} 2$ Atom, the $\mathrm{Kb}$ Ketone and the Eb Enol at the $\mathrm{O} 1$ Atom<smiles></smiles>

Ka

Ea<smiles></smiles><smiles></smiles>

Kb<smiles>[R][R]=[R]=[R]</smiles>

$\omega$ B97X-D placing Ea substantially higher in energy than when using M06-2X. This disagreement mirrors the previous reported issues in predicting relative energy values for the neutral keto and enol tautomers of dibenzoylmethane systems without anharmonic methods. ${ }^{27,69}$ Many of these previous papers also identified twisted $Z$ and $E$ rotamer geometries. Our conformational search identified many such twisted forms, but their relative energies lay at much higher energies ( $>40$ and 30 $\mathrm{kJ} / \mathrm{mol}$ using the $\omega \mathrm{B} 97 \mathrm{X}-\mathrm{D}$ and M06-2X functionals, respectively) so they have been omitted from this work. The high energy of the twisted geometries highlights the electronic stability of the planar, hyperconjugated, $\mathrm{AB} \cdot \mathrm{H}^{+}$ion.

As noted above, the $\mathbf{K b}$ isomer only exists as a geometric minimum when optimized using the $\omega$ B97X-D functional and with a solvent present. Figure 1 shows the relaxed coordinate scan between $\mathbf{K a}$ and $\mathbf{K b}$ proton transfer geometries as a function of the $\mathrm{O} 2 \mathrm{H}$ bond distance from 1.05 to $1.50 \AA$ (a relaxed energy minimization at the $\omega \mathrm{B} 97 \mathrm{X}-\mathrm{D} / \mathrm{def} 2-\mathrm{SVP}$ level was performed at each scan coordinate). The calculated intermolecular hydrogen bond length is 1.41 and $1.46 \mathrm{E}$ in the gas phase and in ethanol, respectively. Our calculations reveal that while a $4 \mathrm{~kJ} / \mathrm{mol}$ energy difference exists between the proton transfer isomers there is no barrier to this reaction in the absence of solvent. In ethanol, there exists a very small 1 $\mathrm{kJ} / \mathrm{mol}$ barrier to the shallow potential well. Nonetheless, the 
Table 1. Calculated Relative Energies of $\mathrm{AB} \cdot \mathrm{H}^{+}$and Population Analysis. Values in Parentheses Were Calculated in Ethanol Solvent. NM = No Minima Found

\begin{tabular}{|c|c|c|c|c|c|c|}
\hline \multirow[b]{2}{*}{ structure } & \multicolumn{3}{|c|}{ relative energy $\left(\mathrm{kJ} \mathrm{mol}^{-1}\right)^{a}$} & \multicolumn{3}{|c|}{ population $(\%)^{b}$} \\
\hline & $\omega \mathrm{B} 97 \mathrm{X}-\mathrm{D}$ & M06-2X & B3LYP & $\omega \mathrm{B} 97 \mathrm{X}-\mathrm{D}$ & M06-2X & B3LYP \\
\hline $\mathrm{Ka}$ & $0(0)$ & $0(0)$ & $0(0)$ & $99(77)$ & $75(83)$ & $84(91)$ \\
\hline $\mathbf{K b}$ & NM (4) & NM (NM) & NM (NM) & NM (23) & NM (NM) & $\mathrm{NM}(\mathrm{NM})$ \\
\hline Ea & $16(17)$ & $4(6)$ & $8(11)$ & \multirow{2}{*}{$<1(<1)$} & $20(12)$ & $11(6)$ \\
\hline $\mathbf{E b}$ & $20(20)$ & $9(9)$ & $12(13)$ & & $4(5)$ & $4(3)$ \\
\hline
\end{tabular}

${ }^{a}$ Relative electronic energy values are zero-point energy corrected. ${ }^{b}$ Boltzmann probability distribution calculated at $100{ }^{\circ} \mathrm{C}$ from relative energy difference column values.

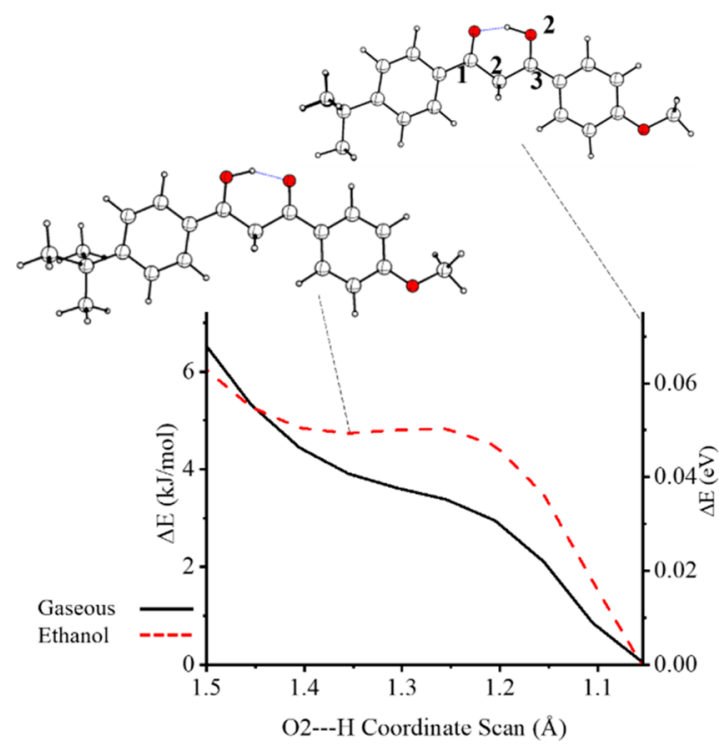

Figure 1. Coordinate energy scans about the $\mathrm{O} 2-\mathrm{H}$ bond, presented with selected molecular structures.

$\mathbf{K b}$ isomer exists by way of a motional resonance with $\mathbf{K a}$ due to the in-plane intermolecular hydrogen bond. A symmetric $\mathrm{C} 2 / \mathrm{O} 2 / \mathrm{H}$ in-plane bend (section $\mathrm{S} 1$ ) defines the $\mathbf{K b} \leftarrow \mathbf{K a}$ proton migration and has a zero-point energy of $0.28 \mathrm{eV}$.

TD-DFT calculations were performed to determine the electronic excitations of the $\mathbf{K a}, \mathbf{E a}$, and $\mathbf{E b}$ structures. The resulting simulated electronic spectra are presented in Figure 2 for excitation energies between 2.5 and $6.0 \mathrm{eV}$ and reveal that the absorption spectra associated with the low-energy cis structures, $\mathbf{K a}$ and $\mathbf{E a} / \mathbf{E b}$, are quite different. The same was observed previously in experiments on neutral $A B,{ }^{35,40}$ and is directly related to the substantial change of electron density within the pseudocyclic moiety that occurs upon keto-enol tautomerization. ${ }^{27}$ Three calculated spectra are overlaid for each isomer to explore the effect of changing functional. The Ka spectrum shows good agreement between the different dispersive functional treatments, while the PBE0 spectrum is red-shifted by $0.2 \mathrm{eV}$. The convolved spectral shape of $\mathrm{Ka}$ is nearly identical for all functionals chosen here, with each calculation predicting a strong transition followed by a medium strength transition $0.5 \mathrm{eV}$ higher in energy. The Ea spectral profile is also similar for each of the dispersive functionals, with the PBE0 spectrum red-shifted by $0.26 \mathrm{eV}$. The convolved spectral shape of Ea shows two well-separated transitions, with the most intense being the lower-energy transition. Similar results were obtained for the $\mathbf{E b}$ tautomer, with the spectrum being red-shifted by $0.06 \mathrm{eV}$ compared to Ea. The difference between the most intense $\mathrm{Ka}$ and Ea transitions is $0.76 \mathrm{eV}$.

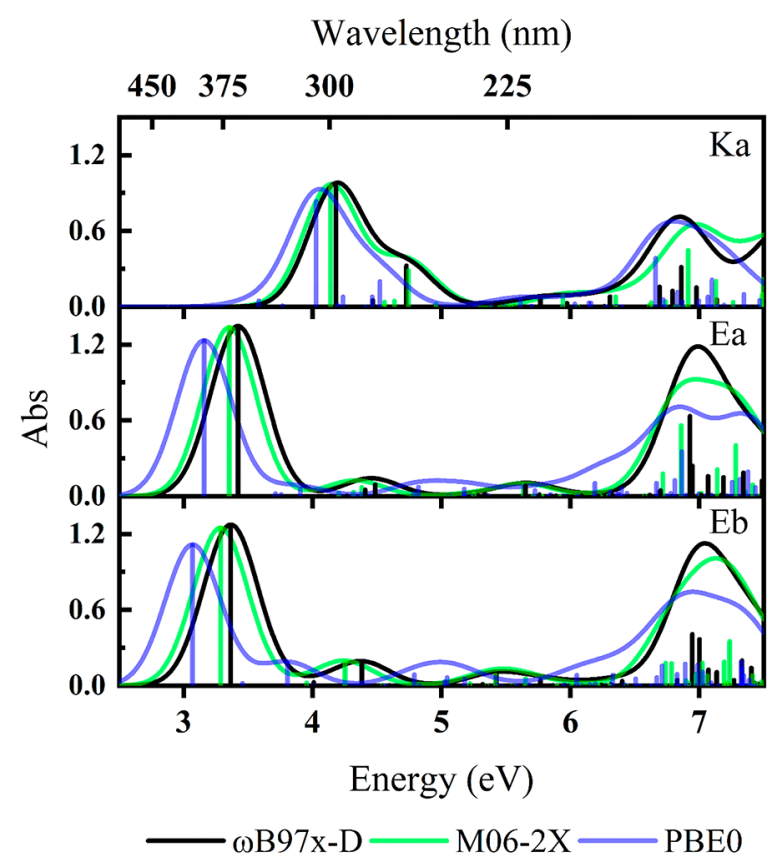

Figure 2. Calculated gas-phase TD-DFT excitation energies and simulated electronic absorption spectra $(\omega \mathrm{B} 97 \mathrm{X}-\mathrm{D}, \mathrm{M} 06-2 \mathrm{X}, \mathrm{PBE} 0)$ for $\mathbf{K a}, \mathbf{E a}$, and $\mathbf{E b}$. Oscillator strengths of individual transitions are given as vertical bars, while the full line spectrum is a convolution of the calculated transitions with a Gaussian function (0.5 eV FWHM). Excitation energies are presented unshifted.

3.2. IRMPD Spectroscopy of $A B \cdot \mathrm{H}^{+}$. Figure 3 shows the IRMPD total ion yield spectra of $\mathrm{AB} \cdot \mathrm{H}^{+}$(summed from yield spectra of photofragments at $m / z 135$ and 161 (major) and $m /$ $z 177$ (minor) and $m / z 255$ (minor)), overlaid with the calculated vibrational spectrum of $\mathbf{K a}, \mathbf{E a}$, and $\mathbf{E b}$. The $\mathbf{K a}$ species is predicted to have a dominant vibrational band at $1420 \mathrm{~cm}^{-1}$. A strong vibrational feature is evident in the experimental spectra in this region, consistent with Ka being present in the experimental ion ensemble. For the $\mathbf{E a} / \mathbf{E b}$ tautomers, the dominant vibrational band over the scanned spectral region is predicted to occur at $1562-5 \mathrm{~cm}^{-1}$. We assign the experimental feature at $1575 \mathrm{~cm}^{-1}$ to this $\mathbf{E a} / \mathbf{E b}$ tautomer vibration. The experimental spectrum is therefore consistent with both $\mathbf{K a}$ and $\mathbf{E a} / \mathbf{E b}$ tautomers being present in the electrospray ion ensemble, as predicted by the $a b$ initio population analysis reported in section 3.1. The spectral features that occur across the $1100-1350 \mathrm{~cm}^{-1}$ region could be attributed to either keto or enol tautomers and so are not discussed in detail here. A series of composite calculated Ka and Ea infrared spectra (Section S2) support our assignment of 


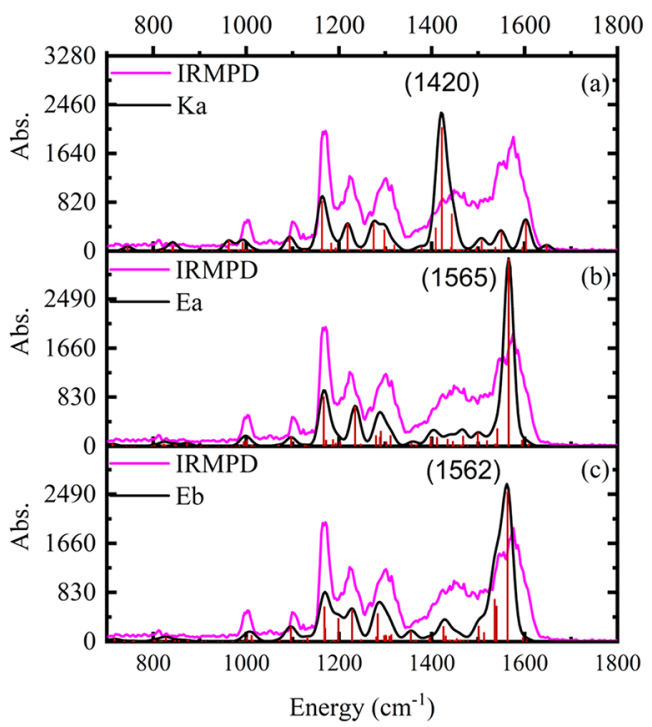

Figure 3. IRMPD spectrum of $\mathrm{AB} \cdot \mathrm{H}^{+}$(in pink) is shown overlaid with simulated spectra (in black) for (a) Ka, (b) Ea, and (c) Eb. The calculated frequencies are scaled by 0.97 .

the IRMPD spectrum as arising from a combination of $\mathbf{K a}$ and $\mathbf{E a} / \mathbf{E b}$ tautomers.

3.3. Gas-Phase UV Absorption Spectrum of $A B \cdot H^{+}$. Figure $4 \mathrm{a}$ displays the gas-phase absorption photodepletion

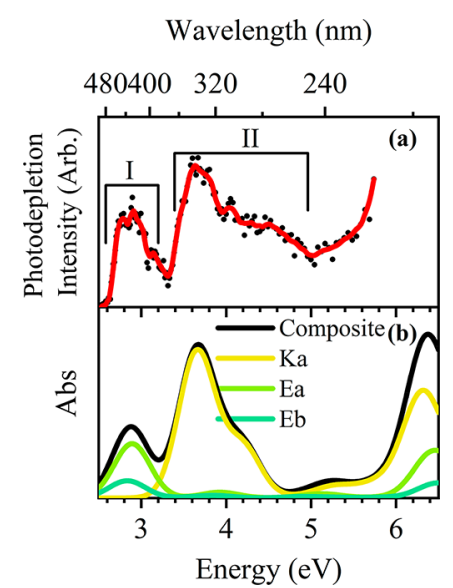

Figure 4. (a) Gas-phase photodepletion spectrum of $\mathrm{AB} \cdot \mathrm{H}^{+}$. The solid line is a 5-point adjacent average of the data points. (b) Composite TD-DFT curves for Ka, Ea, Eb at the $\omega$ B97X-D/def2-SVP level. The TD-DFT calculated electronic transitions have been redshifted by $0.53 \mathrm{eV},{ }^{70}$ and intensities weighted by the Boltzmann populations.

spectra of $\mathrm{AB} \cdot \mathrm{H}^{+}(\mathrm{m} / z 311)$ over the range $2.5-5.7 \mathrm{eV}$. There are two distinct bands, labeled I and II, with $\lambda_{\max }$ values at 2.9 and $3.6 \mathrm{eV}$, respectively. We note that the falling edge of band I contains a minor shoulder which is likely to be an experimental artifact caused by an OPO crystal changeover at that energy. Band II is asymmetric with an extended shoulder to higher energies. The photodepletion spectrum was recorded under single-photon absorption conditions, confirmed by power studies at the $\lambda_{\max }$ of bands I and II (section S3).

The main features of the experimental photodepletion spectrum can be well reproduced by the calculated gas-phase absorption spectrum (Figure $4 \mathrm{~b}$ ), which sums the TD-DFT spectra of the $\mathbf{K a}, \mathbf{E a}$, and $\mathbf{E b}$ isomers (Section 3.1). (The contributions of each isomer are scaled to match the calculated gas-phase Boltzmann populations (Table 1) and the calculated electronic transitions have been red-shifted by $0.53 \mathrm{eV}$ to match the observed experimental band positions). ${ }^{70}$ This allows confident assignment of band $I$ to the bright $S_{1}$ transitions of the $\mathbf{E a / E b}$ pair of isomers, and band II to bright $S_{1}$ and $S_{3}$ transitions of the Ka isomer (note that depending on the functional used there are minor contributions from weak transitions within band II and small differences in the ordering of states $S_{1}-S_{4}$ ). We note that the increase in photodepletion signal above band II is poorly matched to the minor feature at $5.2 \mathrm{eV}$ of the composite TD-DFT; however, there is a strong feature at $6.4 \mathrm{eV}$ which likely corresponds to this region.

3.4. UV Photofragmentation of $\mathrm{AB} \cdot \mathrm{H}^{+}$. Figure 5 displays the photofragment difference mass spectra of $\mathrm{AB} \cdot \mathrm{H}^{+}$photo-

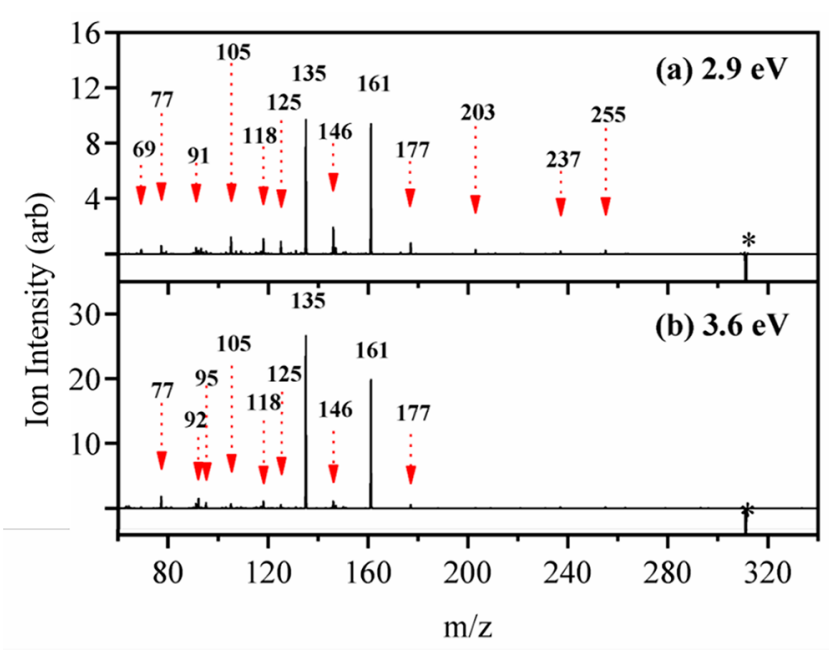

Figure 5. Photofragment difference (laser on-laser off) mass spectrum of $\mathrm{AB} \cdot \mathrm{H}^{+}$excited at (a) $2.9 \mathrm{eV}$, and (b) $3.6 \mathrm{eV}$. The asterisk $(*)$ represents the depleted parent ion signal at $m / z 311$.

excited at the band I and II maxima (2.6 and $3.6 \mathrm{eV}$, respectively). The dominant photofragments observed are $\mathrm{m} / z$ 161 [eq 4a] and $m / z 135$ [eq $4 \mathrm{~b}$ ], with both being products of McLafferty-like retro-heteroene hydrogen rearrangements adjacent to the $\mathbf{a}$ and $\mathbf{b}$ protonation centers. ${ }^{71}$

$$
\begin{aligned}
\mathrm{AB} \cdot \mathrm{H}^{+}+h \nu & \rightarrow \mathrm{C}_{9} \mathrm{H}_{10} \mathrm{O}_{2}+\mathrm{m} / \mathrm{z} 161 \\
& \rightarrow \mathrm{C}_{14} \mathrm{H}_{8}+\mathrm{m} / \mathrm{z} 135
\end{aligned}
$$

In addition to the hydrogen rearrangement products, several minor photofragments are produced across all probed wavelengths. Two of the more prominent minor photofragments are $m / z 146$ [eq 4c] and $m / z 177$ [eq 4d].

$$
\begin{aligned}
\mathrm{AB} \cdot \mathrm{H}^{+}+h \nu & \rightarrow \mathrm{C}_{10} \mathrm{H}_{14}+\mathrm{CH}_{3} \mathrm{O}^{\bullet}+\mathrm{m} / \mathrm{z} 146 \\
& \rightarrow \mathrm{C}_{10} \mathrm{H}_{14}+\mathrm{m} / \mathrm{z} 177
\end{aligned}
$$

These photoproducts arise from proton transfer from a carbonyl to a ring group, with subsequent elimination of neutral molecules. The $m / z 146$ fragment is an unusual oddelectron photofragment, which is not produced in the collision induced dissociation (CID) of $\mathrm{AB} \cdot \mathrm{H}^{+}$(section S4). However, 
Table 2. Proposed Structures for the Major Ionic and Associated Neutral Fragments of AB $\cdot \mathrm{H}^{+}(\mathrm{m} / z$ 311$)$ Produced during CID and UV Laser Photoexcitation

\begin{tabular}{|c|c|c|c|c|c|}
\hline $\begin{array}{c}\text { Fragment } \\
\text { Mass } \\
(\mathrm{m} / \mathrm{z})\end{array}$ & $\begin{array}{c}\text { Proposed Structure of } \\
\text { Fragment }\end{array}$ & $\begin{array}{c}\mathbf{m} / \mathbf{z} \\
\text { lost } \\
\text { from } \\
\text { AB· } \mathbf{H}^{+}\end{array}$ & $\begin{array}{c}\text { Fragment } \\
\text { Results from } \\
\text { Loss of Neutral }\end{array}$ & $\begin{array}{l}\text { Observed } \\
\text { in CID }{ }^{a, b}\end{array}$ & $\begin{array}{l}\text { Observed in UV } \\
\text { Laser } \\
\text { Photoexcitation a }\end{array}$ \\
\hline 255 & & 56 & & $\checkmark \quad(\mathrm{m})$ & $\checkmark \quad(w)$ \\
\hline 177 & & 134 & & $\checkmark \quad(\mathrm{m})$ & $\begin{array}{ll}\checkmark \quad(w)\end{array}$ \\
\hline 161 & & 150 & & $\begin{array}{ll}\checkmark & (\mathrm{s})\end{array}$ & $\begin{array}{ll}\checkmark & (\mathrm{s})\end{array}$ \\
\hline 146 & & $134+31$ & & & $\checkmark \quad(w)$ \\
\hline 135 & $\mathrm{O}_{-}^{\oplus}$ & 176 & & $\begin{array}{ll}\checkmark & (\mathrm{s})\end{array}$ & $\begin{array}{ll}\checkmark \quad(v s)\end{array}$ \\
\hline
\end{tabular}

${ }^{a}$ Notation: very strong (vs), strong (s), medium (m), and weak (w). ${ }^{b}$ The IRMPD photofragments are identical to the CID fragments listed here and have similar relative intensities.

$m / z 147$ is measured in both CID and UVPD studies, but only nominally by the latter measurement. This is a notable observation since the $m / z 146$ fragment, and the accompanying free radical(s), are therefore produced from $\mathrm{AB} \cdot \mathrm{H}^{+}$ following UVA excitation only. Table 2 presents proposed structural assignments of the major observed $\mathrm{AB} \cdot \mathrm{H}^{+}$photofragment ions, as well as those produced by thermal fragmentation (CID; section S4). Additional minor fragmentation channels are tabulated in section S4.

To determine whether any of the observed photofragments arise from secondary fragmentation, the major photofragment ions $\mathrm{m} / z 161$ and $\mathrm{m} / z 135$ were isolated in the ion trap and then subjected to photoexcitation. The resulting photofragment action spectra are displayed in section S5 and reveal that neither $\mathrm{m} / z 161$ nor $\mathrm{m} / \mathrm{z} 135$ directly photofragments to produce any other observed photofragments.

Figure 6 displays a plot of the wavelength-dependent relative ion yields of the key $\mathrm{AB} \cdot \mathrm{H}^{+}$photofragments, providing a concise overview of the photofragment branching ratios. Full photofragment action spectra are included in section S5. At the maxima of band I $(2.9 \mathrm{eV})$ the major fragment ions $\mathrm{m} / z 161$ and $m / z 135$ appear in equal proportions with each accounting for roughly $32 \%$ of the total photofragmentation signal. The onset of band II $(3.3 \mathrm{eV})$ sees an increase in the relative ion intensity of $m / z 135$, with peaks in production of this ion at 3.4 and $4.3 \mathrm{eV}$ (where it constitutes $50 \%$ and $60 \%$ of the total photofragmentation, respectively). The relative intensity of the $\mathrm{m} / z 161$ photofragment falls to $25 \%$ at these energies. At photon energies above $4.8 \mathrm{eV}$, the relative ion intensities of the $\mathrm{m} / z 161$ and $\mathrm{m} / z 135$ pair of photofragments are again

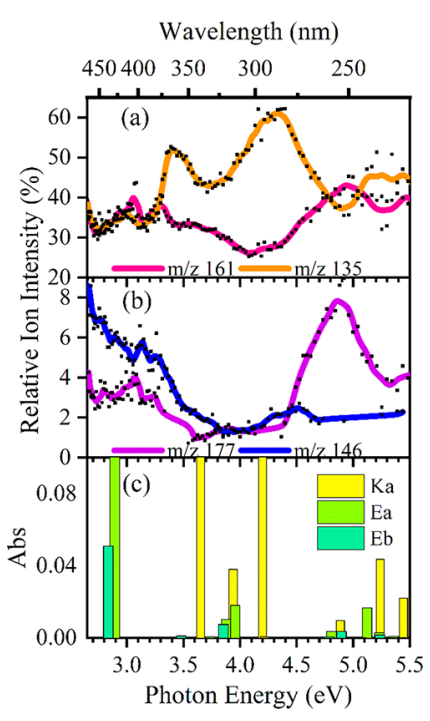

Figure 6. Relative ion yield plots for (a) the $m / z 161,135$, (b) $\mathrm{m} / z$ 146,177 photofragments of $\mathrm{AB} \cdot \mathrm{H}^{+}$between 2.6 and $5.5 \mathrm{eV}$, and (c) the TD-DFT calculated excitation energies for each isomer at the $\omega$ B97X-D/def2-SVP level. The curved lines included with the data points are a five-point adjacent average of such data points. Calculated excitation energies have been red-shifted by $0.53 \mathrm{eV}$.

approximately equal, with the total branching into these fragments being slightly higher than in the band I region.

The $m / z 146$ fragment is produced most intensely in the low-energy spectral region between 2.7 and $3.6 \mathrm{eV}$, with its relative intensity decreasing across the band I region from $8 \%$ to $3 \%$, and with a small enhancement in production around 4.5 
$\mathrm{eV}$. The $m / z 177$ ion is similar across the band I region, with respect to the $m / z 146$ spectrum. Between 4.5 and $5.2 \mathrm{eV}$, the relative ion intensity of $\mathrm{m} / z 177$ increases dramatically, peaking strongly around $4.7 \mathrm{eV}$. Notably, this peak in production of $\mathrm{m} / z 177$ does not follow the same profile as band II of the photodepletion spectra, but does coincide with a pair of predicted weak Ea and Eb excitations at 4.8 and $4.9 \mathrm{eV}$ (Figure 6c).

Approximately $15-20 \%$ parent ion depletion $\left(I_{\text {off }}-I_{\text {on }}\right)$ is not recovered as measurable photofragmentation signal, an effect that can be attributed to production of ion fragments with $\mathrm{m} / \mathrm{z}$ $<50$ which is below the instrumental low mass cutoff. For example, heterolytic dissociation of the $\mathrm{R}_{2}$-bound methoxy group would produce an even-electron ion at $\mathrm{m} / \mathrm{z} 31$ along with zwitterionic $\mathrm{C}_{19} \mathrm{H}_{20} \mathrm{O}_{2}$.

Finally, it is useful to review the photofragments produced compared to those observed via CID. CID, like IRMPD, is equivalent to thermal-induced dissociation and produces socalled statistical fragments. ${ }^{41}$ For $\mathrm{AB} \cdot \mathrm{H}^{+}$, CID produces $\mathrm{m} / \mathrm{z}$ 161 and $m / z 135$ as the dominant ionic products (Figure S8), with approximately equal intensity. Notably, these are the major photofragments observed in this study. From the relative ion intensities shown in Figure 6, it is evident that production of the $\mathrm{m} / z 161$ and $\mathrm{m} / z 135$ pair of photofragments is broadly statistical in the regions from 2.7 to $3.2 \mathrm{eV}$ (i.e., the band I region), and above $5 \mathrm{eV}$ (i.e., above band II). However, in the region between 3.7 and $4.7 \mathrm{eV}$ (vis to near-UVA), photofragmentation is clearly nonstatistical with production of the $\mathrm{m} / z 135$ photofragment being photochemically enhanced. $^{42,72-76}$

\section{DISCUSSION}

4.1. Mechanisms of Dissociation for the $\mathrm{Ka}$ and $\mathrm{Ea} / \mathrm{Eb}$ Isomers of Protonated Avobenzone. From the calculated TD-DFT spectra presented in section 3.1, excitations associated with the $\mathrm{Ka}$ tautomer dominate in the region between 3.7 and $5.0 \mathrm{eV}$, while $\mathbf{E a} / \mathbf{E b}$ excitations dominate for energies between 2.5 and $3.7 \mathrm{eV}$. One of the striking features of the ion yield production spectra is that production of the $\mathrm{m} / \mathrm{z}$ 135 photofragment peaks strongly at 3.6 and $4.3 \mathrm{eV}$. These energies coincide with the calculated bright transitions for the $\mathrm{Ka}$ tautomer (Figure 6c), leading to the conclusion that enhanced production of the $\mathrm{m} / z 135$ photofragment follows excitation of keto tautomer transitions. At the energies where production of $\mathrm{m} / z 135$ is enhanced, the relative ion intensity of $\mathrm{m} / z 161$ decreases, which is expected for a relative ion intensity plot (i.e., if one relative ion intensity increases, another ion intensity must decrease).

Scheme 3 presents the proposed fragmentation pathways for the $m / z 161$ and $m / z 135$ fragments, associated with hydrogen rearrangement within the protonated diketo bridge of $\mathrm{Ka}$. Since the odd-electron $\mathrm{m} / z 162$ and $\mathrm{m} / z 136$ photofragments are not observed, we can rule out direct $\alpha$-cleavage of the Ka and $\mathbf{K b}$ tautomers, as occurs for the corresponding neutral tautomers in solution. ${ }^{32}$ Instead, a retro-heteroene addition of the $\gamma$-hydrogen (charge carrier) to the $\mathbf{K a}$ and $\mathbf{K b}$ tautomers generates the $\mathrm{m} / z 135$ and $\mathrm{m} / z 161$ ions, respectively (Kb is included in this scheme, as it was established (section 3.1) to be vibrationally populated by $\mathbf{K a}$ ). The Scheme 3 mechanism resembles the classic McLafferty rearrangement for ionic and radical molecules containing a keto group which undergoes $\beta$ cleavage. $^{71,77-80}$ (For $\mathrm{AB} \cdot \mathrm{H}^{+}$, a protonated heteroatom occupies the saturated $\gamma$-carbon position typical to McLafferty
Scheme 3. Proposed McLafferty-like Rearrangement to Form Products $4 \mathrm{~b}$ and $4 \mathrm{a}$
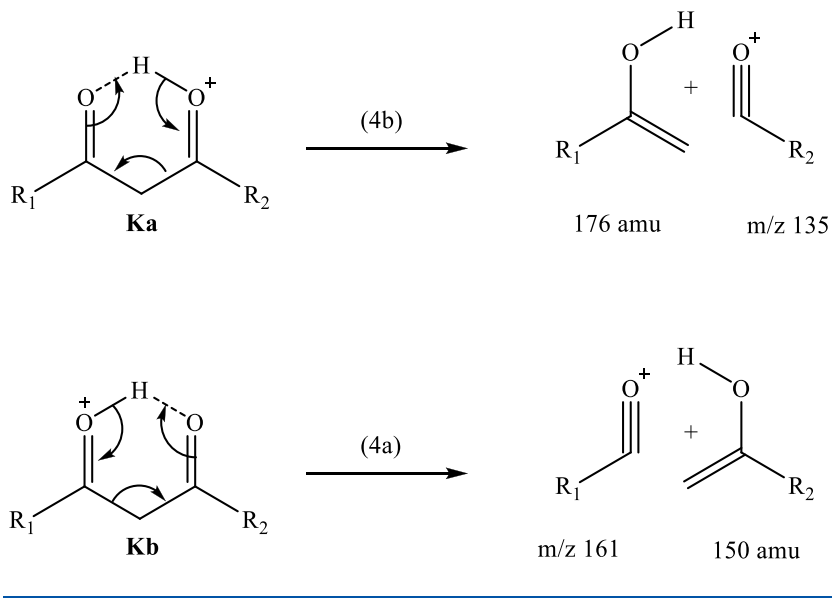

systems.) Scheme 3 illustrates that the $\mathrm{m} / z 161$ and $\mathrm{m} / z 135$ fragments can be produced in a straightforward mechanism from a keto tautomer, but no similar McLafferty-like rearrangement can be deduced from an enol tautomer (the reduced $\mathrm{C} 2 \beta$-carbon of either $\mathbf{E a} / \mathbf{E b}$ species needs an additional hydrogen for this reaction (as shown) to occur). Thus, Scheme 3 provides further evidence that $\mathrm{m} / \mathrm{z} 161$ and $m / z 135$ derive from $\mathbf{a} \mathbf{K a} / \mathbf{K b}$ tautomer.

The ion fragments $m / z 177$ and $m / z 146$ are photoproducts which can be assigned as being unique to the isomer Ea. The spectral profile traces of $m / z 177$ and $m / z 146$ shown in Figure $6 \mathrm{~b}$ match the computed spectra of $\mathbf{E a} / \mathbf{E b}$ (Figure $6 \mathrm{c}$ ). Scheme 4a presents a tentative mechanism for the formation of $\mathrm{m} / \mathrm{z}$ 177 from Ea via a proton transfer from the enol to the nearby ring. Following this transfer a ring-walk and subsequent elimination yields the detected ion fragment. The proton transfer ring-walk mechanism proposed here is akin to those proposed previously for fragmentation patterns of elimination substitution (ortho, meta, para) of aromatic systems. ${ }^{81-83}$ An analogous mechanism from the Eb isomer (not shown) would yield the $m / z 255$ ion fragment which was measured with very low intensity and therefore omitted from Figure $6 \mathrm{~b}$. At the same time, the observation of the $\mathrm{m} / z 255$ photofragment indicates that $\mathbf{E b}$ is present at low concentration in our ion ensemble. Scheme $4 \mathrm{~b}$ includes the homogeneous dissociation of the $\mathrm{R}_{2}$-methoxy group followed by a mechanism similar to 4 a to yield $m / z 146$.

4.2. Implied Photodynamics of $\mathrm{Ka}$ and $\mathrm{Ea} / \mathrm{Eb}$ Conformers. Previous work by Dunkelberger et al. ${ }^{25}$ on neutral $\mathrm{AB}$ in solution measured nonradiative formation of transient hot ground-state intermediates formed upon excitation of the $\mathrm{CE}$ form. These transients were found to be accessed by a series of largely rotational coordinate-driven conical intersections (CIs) in less than 1 ps, with the chelation of CE being broken by either out-of-plane $\mathrm{OH}$ motion, or $\mathrm{C} 1-\mathrm{C} 2, \mathrm{C} 2-\mathrm{C} 3$ centered dihedral (i.e., twisted) rotations. Solvent effects were found to influence the relaxation rates back to the $\mathrm{CE}$ equilibria, with the rotated $\mathrm{OH}$ form being the most rapid to equilibrate at $\tau=1.3 \mathrm{ps}$, while the twisted forms displayed tens of picoseconds to microsecond-millisecond measured lifetimes. A CI was identified along the intramolecular proton transfer tautomerization coordinate which had a relaxation lifetime of 6 ps. Overall, these observations revealed that the 
Scheme 4. Proposed Product Formation from the AB $\cdot \mathrm{H}^{+}$Enol Tautomers by (a) Proton Transfer Preceding Ring-Walk and Elimination [4d] and by (b) Homolytic Fission of the $R_{2}$-Methoxy Bond Prior to Proton Transfer Preceding Ring-Walk and Elimination [4c]. Dotted Arrows Indicate the Proposed Reaction Path. $*_{m} / z 280$ Is Not Detected

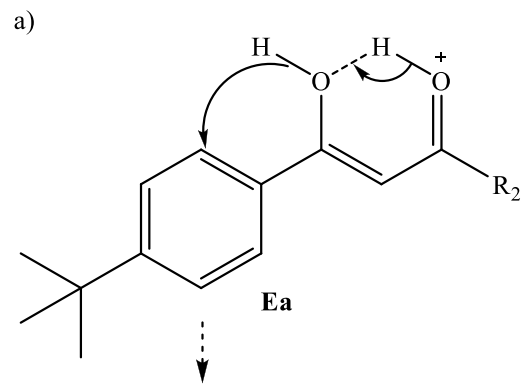<smiles>[R]C(=O)CC#[O+]</smiles><smiles>[R]C1=CC(c2ccc(C(C)(C)C)cc2)=C[IH]O1</smiles><smiles>[R2]C1=CC(Cc2ccc(C(C)(C)C)cc2)=C[Hg]O1</smiles>

b)

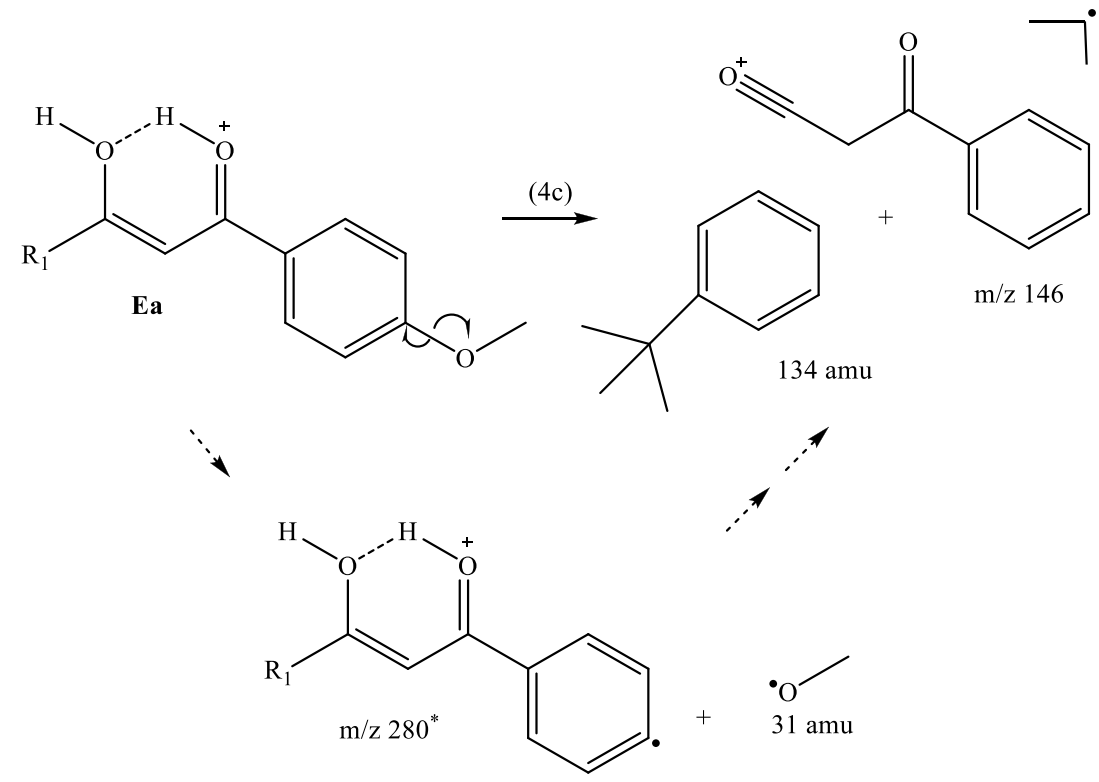

rate of enol to keto tautomerization for the neutral in solution is low.

It is useful to consider how the known photodynamics of the neutral change upon protonation. From the discussion above, it is clear that pathways involving the $\mathrm{OH}$ group (i.e., out-ofplane $\mathrm{OH}$ rotation and tautomerization) play key roles in the decay dynamics. Protonation is highly likely to disrupt these pathways, since protonation of the carbonyl of the $\mathrm{CO}$ of the $\mathrm{CE}$ will lead to a decrease in the intramolecular hydrogen-bond strength.

Given that $\mathrm{AB} \cdot \mathrm{H}^{+}$produces the $m / z \quad 135$ and 161 photofragments across the $\mathbf{E a} / \mathbf{E b}$ excitation wavelengths, and the fact that $\mathbf{E a} / \mathbf{E b}$ structures cannot produce these product ions (section 4.1), our results indicate that enol to keto photoisomerization $\mathrm{AB} \cdot \mathrm{H}^{+}$must be occurring, followed by subsequent degradation into $\mathrm{m} / z 135$ and 161 . Even at the peak of $\mathbf{E a} / \mathbf{E b}$ absorption $(2.9 \mathrm{eV}), 75 \%$ of the detected photofragments arise from keto structures. For neutral $A B$, enol to keto tautomerization has a very low cross-section from the measured rates. ${ }^{25,30,40}$ If we assume that the photofragment cross-section is directly proportional to the relaxation rates of the initially populated excited states into photoproducts, then our experiment suggests that the cross-section for dissociative excited-state decay observed for $\mathrm{AB} \cdot \mathrm{H}^{+}$is substantially greater than for $\mathrm{AB}$ in solution. One explanation of this observation is that protonation lowers the energetic barriers to "twisting" mechanisms that enhance enol to keto photoisomerization. High level computational potential energy scans of transition state geometries would be valuable to clarify this and solutionphase studies on the protonates species are clearly warranted.

This work has shown that the protonation of the $\beta$-diketone bridge is responsible for a shift from type I to II photoelimination of $A B \cdot{ }^{31,84}$ Neutral $A B$ in solution is known to undergo Norris Type I (photoinitiated $\alpha$-cleavage) dissociation and subsequent recombination. ${ }^{32}$ This dissociation process produces radical fragments aided, in part, by the long-range 
repulsive force of an excited triplet spin-state. ${ }^{31}$ Norris Type II reactions, which are analogous to thermally activated McLafferty rearrangements seen in mass spectrometry, rely on the acidic nature of excited states to access an $S_{0} \leftarrow S_{1} / T_{1}$ CI by way of a downhill $\gamma$-hydrogen potential coordinate, widely known as excited-state intramolecular proton transfer. ${ }^{31,84-86}$ Whether the photodegradation of $\mathbf{E a / E b}$ proceeds through an excited triplet state cannot be directly experimentally identified here. However, the observation of the $\mathrm{m} / \mathrm{z}$ 146 photofragment (a free-radical fragment) is indicative of fragmentation via a triplet state.

Computational work on neutral $\mathrm{AB}$ by Kojić et al. showed that under both gaseous and solvated conditions $(\mathrm{MeCN})$, the $S_{1}$ state of CE has a $T_{1}$ state of alternate spin parity available energetically within the zero-point-energy window of $S_{1}$ at the Franck-Condon geometry. ${ }^{27}$ If $\mathrm{T}_{1}$ is accessed, there is a flat potential about the out-of-plane $\mathrm{OH}$ dihedral coordinate which crosses the contorted $S_{0}$ state. An easily accessible $T_{1}$ state for $\mathbf{E a} / \mathbf{E b}$ at $S_{1}$ Franck-Condon geometries may facilitate the rearrangements shown in Scheme 4. Future calculations of the excited state potential energy surfaces would be valuable to provide further insight into the photophysics.

\section{CONCLUDING REMARKS}

In summary, we have investigated the photochemistry of selected enol and keto isomers of protonated avobenzone in the gas phase. IRMPD spectroscopy was employed to confirm the presence of both enolic $(\mathbf{E a} / \mathbf{E b})$ and diketone $(\mathbf{K a})$ isomers of $\mathrm{AB} \cdot \mathrm{H}^{+}$in the electrosprayed ion ensemble. The dominant electronic excitations of the enol and keto tautomers of gaseous $\mathrm{AB} \cdot \mathrm{H}^{+}$were found to be well separated, allowing us to determine the tautomer-dependent photofragmentation products. Such measurements would be extremely challenging to perform in solution, due to the solution-phase tautomers displaying overlapping spectral profiles. Analysis of the wavelength-dependent production of the various photofragments revealed that near-UVA photoexcitation provides a route to enol-to-keto tautomerization, consistent with previously proposed mechanisms for photodegradation of avobenzone in the condensed phase. Finally, we observed oddelectron photofragments in low quantum yield from the enol tautomer of $\mathrm{AB} \cdot \mathrm{H}^{+}$, which indicates that a previously unidentified photosensitizing pathway is present for this isomer. Prior studies of the neutral $\mathrm{AB}$ system have identified triplet excited states for the keto form.

We note that gas-phase photoisomerization has been studied by Bieske and co-workers, using ion mobility to detect photoisomers generated from protonated azobenzones. ${ }^{87-89}$ Sheps and co-workers have performed an elegant series of experiments on gaseous neutral acetylacetone (a prototypical $\beta$-diketone), to probe keto to enol tautomerization using a combination of photoionization techniques. ${ }^{90}$ However, work presented here provides an important complement to these earlier studies since it demonstrates a method for directly detecting the photoproducts of a photoisomerizing system.

In the context of the current study of $\mathrm{AB} \cdot \mathrm{H}^{+}$, it is useful to compare the results to our previous work on protonated oxybenzone, $\mathrm{OB} \cdot \mathrm{H}^{+}$. Oxybenzone is another widely used UV sunscreen, and provides an interesting contrast to $A B$ since it is known to exhibit excellent photostability. ${ }^{4,91-94}$ The OB. $\mathrm{H}^{+}$ contains a pseudocycle, formed by the intramolecular bond between the hydroxy and carbonyl groups. The McLafferty-like elimination reaction responsible for the most intense $\mathrm{AB} \cdot \mathrm{H}^{+}$ fragments cannot be produced straightforwardly from the enolic tautomers of $\mathrm{AB} \cdot \mathrm{H}^{+}$, or similarly, from $\mathrm{OB} \cdot \mathrm{H}^{+}$due to the pseudocyclic nature of both structures. Moreover, while an enol-to-keto tautomerization in $\mathrm{AB} \cdot \mathrm{H}^{+}$can lead to this elimination reaction, the direct conjugation of the pseudocycle and benzene ring in $\mathrm{OB} \cdot \mathrm{H}^{+}$restricts this reaction pathway. Such comparative measurements are valuable for gaining a broader understanding of the molecular-level performance of different sunscreen molecules, and may be useful in the context of efforts to develop new sunscreen molecules. ${ }^{2,95}$

\section{ASSOCIATED CONTENT}

\section{Supporting Information}

The Supporting Information is available free of charge at https://pubs.acs.org/doi/10.1021/acs.jpca.0c01295.

Additional DFT and TD-DFT calculations; composite $\mathrm{AB} \cdot \mathrm{H}^{+}$IR $\mathrm{Ka}$ and Ea spectra; photodepletion laser power dependence; Collision induced dissociation measurements on $\mathrm{AB} \cdot \mathrm{H}^{+}$; additional photofragmentation measurements; possible heterolytic cleavage products of $\mathrm{AB} \cdot \mathrm{H}^{+}$isomers (PDF)

\section{AUTHOR INFORMATION}

\section{Corresponding Author}

Caroline E. H. Dessent - Department of Chemistry, University of York, York YO10 5DD, U.K.; 이이이.org/0000-0003-

4944-0413; Email: caroline.dessent@york.ac.uk

\section{Authors}

Jacob A. Berenbeim - Department of Chemistry, University of York, York YO10 5DD, U.K.

Natalie G. K. Wong - Department of Chemistry, University of York, York YO10 5DD, U.K.

Martin C. R. Cockett - Department of Chemistry, University of York, York YO10 5DD, U.K.

Giel Berden - Institute for Molecules and Materials, FELIX Laboratory, Radboud University, Nijmegen 6500 HC, The Netherlands

Jos Oomens - Institute for Molecules and Materials, FELIX Laboratory, Radboud University, Nijmegen 6500 HC, The Netherlands

Anouk M. Rijs - Institute for Molecules and Materials, FELIX Laboratory, Radboud University, Nijmegen 6500 HC, The Netherlands; (1) orcid.org/0000-0002-7446-9907

Complete contact information is available at:

https://pubs.acs.org/10.1021/acs.jpca.0c01295

\section{Notes}

The authors declare no competing financial interest.

\section{ACKNOWLEDGMENTS}

This work was funded through the Leverhulme Trust Research Project Grant RPG-2017-147. We thank the University of York and the Department of Chemistry for provision of funds for the OPO laser system, and the University of York High Performance Computing service, Viking, and the Research Computing team, for the provision of computational resources. We gratefully acknowledge the Nederlandse Organisatie voor Wetenschappelijk Onderzoek (NWO) for the support of the FELIX Laboratory. The research leading to this result has been supported by the project CALIPSOplus under the Grant 
Agreement 730872 from the EU Framework Programme for Research and Innovation HORIZON 2020.

\section{REFERENCES}

(1) Baker, L. A.; Marchetti, B.; Karsili, T. N. V.; Stavros, V. G.; Ashfold, M. N. R. Photoprotection: Extending lessons learned from studying natural sunscreens to the design of artificial sunscreen constituents. Chem. Soc. Rev. 2017, 46, 3770-3791.

(2) Losantos, R.; Funes-Ardoiz, I.; Aguilera, J.; Herrera-Ceballos, E.; Garcia-Iriepa, C.; Campos, P. J.; Sampedro, D. Rational design and synthesis of efficient sunscreens to boost the solar protection factor. Angew. Chem., Int. Ed. 2017, 56, 2632-2635.

(3) Rodrigues, N. D.; Staniforth, M.; Stavros, V. G. Photophysics of sunscreen molecules in the gas phase: A stepwise approach towards understanding and developing next-generation sunscreens. Proc. $R$. Soc. London, Ser. A 2016, 472, 20160677.

(4) Forestier, S. Rationale for sunscreen development. J. Am. Acad. Dermatol. 2008, 58, S133-138.

(5) Ignasiak, M. T.; Houee-Levin, C.; Kciuk, G.; Marciniak, B.; Pedzinski, T. A reevaluation of the photolytic properties of 2 hydroxybenzophenone-based UV sunscreens: Are chemical sunscreens inoffensive? ChemPhysChem 2015, 16, 628-633.

(6) Baker, L. A.; Horbury, M. D.; Greenough, S. E.; Ashfold, M. N.; Stavros, V. G. Broadband ultrafast photoprotection by oxybenzone across the UVB and UVC spectral regions. Photochem. Photobiol. Sci. 2015, 14, 1814-1820.

(7) Baker, L. A.; Horbury, M. D.; Greenough, S. E.; Coulter, P. M.; Karsili, T. N.; Roberts, G. M.; Orr-Ewing, A. J.; Ashfold, M. N.; Stavros, V. G. Probing the ultrafast energy dissipation mechanism of the sunscreen oxybenzone after UVA irradiation. J. Phys. Chem. Lett. 2015, 6, 1363-1368.

(8) Baker, L. A.; Staniforth, M.; Flourat, A. L.; Allais, F.; Stavros, V. G. Gas-solution phase transient absorption study of the plant sunscreen derivative methyl sinapate. ChemPhotoChem. 2018, 2, $743-748$.

(9) Luo, J.; Liu, Y.; Yang, S.; Flourat, A. L.; Allais, F.; Han, K. Ultrafast barrierless photoisomerization and strong ultraviolet absorption of photoproducts in plant sunscreens. J. Phys. Chem. Lett. 2017, 8, 1025-1030.

(10) Peperstraete, Y.; Staniforth, M.; Baker, L. A.; Rodrigues, N. D.; Cole-Filipiak, N. C.; Quan, W. D.; Stavros, V. G. Bottom-up excited state dynamics of two cinnamate-based sunscreen filter molecules. Phys. Chem. Chem. Phys. 2016, 18, 28140-28149.

(11) Tan, E. M.; Hilbers, M.; Buma, W. J. Excited-state dynamics of isolated and microsolvated cinnamate-based UV-B sunscreens. J. Phys. Chem. Lett. 2014, 5, 2464-2468.

(12) Dean, J. C.; Kusaka, R.; Walsh, P. S.; Allais, F.; Zwier, T. S. Plant sunscreens in the UV-B: Ultraviolet spectroscopy of jet-cooled sinapoyl malate, sinapic acid, and sinapate ester derivatives. J. Am. Chem. Soc. 2014, 136, 14780-14795.

(13) Domingos, S. R.; Schnell, M. Wet sunscreens in the gas phase: Structures of isolated and microsolvated oxybenzone. J. Phys. Chem. Lett. 2018, 9, 4963-4968.

(14) Miyazaki, Y.; Yamamoto, K.; Aoki, J.; Ikeda, T.; Inokuchi, Y.; Ehara, M.; Ebata, T. Experimental and theoretical study on the excited-state dynamics of ortho-, meta-, and para-methoxy methylcinnamate. J. Chem. Phys. 2014, 141, 244313.

(15) Rodrigues, N. D.; Staniforth, M.; Young, J. D.; Peperstraete, Y.; Cole-Filipiak, N. C.; Gord, J. R.; Walsh, P. S.; Hewett, D. M.; Zwier, T. S.; Stavros, V. G. Towards elucidating the photochemistry of the sunscreen filter ethyl ferulate using time-resolved gas-phase spectroscopy. Faraday Discuss. 2016, 194, 709-729.

(16) Rodrigo, C. P.; James, W. H., 3rd; Zwier, T. S. Singleconformation ultraviolet and infrared spectra of jet-cooled monolignols: P-coumaryl alcohol, coniferyl alcohol, and sinapyl alcohol. J. Am. Chem. Soc. 2011, 133, 2632-2641.

(17) Fang, Y. G.; Li, C. X.; Chang, X. P.; Cui, G. Photophysics of a UV-B filter 4-methylbenzylidene camphor: Intersystem crossing plays an important role. ChemPhysChem 2018, 19, 744-752.
(18) Li, C. X.; Guo, W. W.; Xie, B. B.; Cui, G. Photodynamics of oxybenzone sunscreen: Nonadiabatic dynamics simulations. J. Chem. Phys. 2016, 145, 074308.

(19) Assis Oliveira, L. B.; Fonseca, T. L.; Costa Cabral, B. J.; Coutinho, K.; Canuto, S. Hydration effects on the electronic properties of eumelanin building blocks. J. Chem. Phys. 2016, 145, 084501.

(20) Marchetti, B.; Karsili, T. N. Theoretical insights into the photoprotective mechanisms of natural biological sunscreens: Building blocks of eumelanin and pheomelanin. Phys. Chem. Chem. Phys. 2016, $18,3644-3658$.

(21) Chang, X. P.; Li, C. X.; Xie, B. B.; Cui, G. Photoprotection mechanism of p-methoxy methylcinnamate: A CASPT2 study. J. Phys. Chem. A 2015, 119, 11488-11497.

(22) Karsili, T. N.; Marchetti, B.; Ashfold, M. N.; Domcke, W. Ab initio study of potential ultrafast internal conversion routes in oxybenzone, caffeic acid, and ferulic acid: Implications for sunscreens. J. Phys. Chem. A 2014, 118, 11999-12010.

(23) Gonzalez, H.; Tarras-Wahlberg, N.; Stromdahl, B.; Juzeniene, A.; Moan, J.; Larko, O.; Rosen, A.; Wennberg, A. M. Photostability of commercial sunscreens upon sun exposure and irradiation by ultraviolet lamps. BMC Dermatol. 2007, 7, 1.

(24) Hanson, K. M.; Narayanan, S.; Nichols, V. M.; Bardeen, C. J. Photochemical degradation of the UV filter octyl methoxycinnamate in solution and in aggregates. Photochem. Photobiol. Sci. 2015, 14, $1607-1616$.

(25) Dunkelberger, A. D.; Kieda, R. D.; Marsh, B. M.; Crim, F. F. Picosecond dynamics of avobenzone in solution. J. Phys. Chem. A 2015, 119, 6155-6161.

(26) Gacoin, P. Studies of the triplet state of carbonyl compounds. I. Phosphorescence of $\beta$-diketones. J. Chem. Phys. 1972, 57, 1418-1425.

(27) Kojic, M.; Petkovic, M.; Etinski, M. A new insight into the photochemistry of avobenzone in gas phase and acetonitrile from $\mathrm{ab}$ initio calculations. Phys. Chem. Chem. Phys. 2016, 18, 22168-22178.

(28) Verma, P. K.; Koch, F.; Steinbacher, A.; Nuernberger, P.; Brixner, T. Ultrafast UV-induced photoisomerization of intramolecularly H-bonded symmetric $\beta$-diketones. J. Am. Chem. Soc. 2014, 136, 14981-14989.

(29) Verma, P. K.; Steinbacher, A.; Koch, F.; Nuernberger, P.; Brixner, T. Monitoring ultrafast intramolecular proton transfer processes in an unsymmetric $\beta$-diketone. Phys. Chem. Chem. Phys. 2015, 17, 8459-8466.

(30) Tobita, S.; Ohba, J.; Nakagawa, K.; Shizuka, H. Recovery mechanism of the reaction intermediate produced by photoinduced cleavage of the intramolecular hydrogen bond of dibenzoylmethane. J. Photochem. Photobiol., A 1995, 92, 61-67.

(31) Marchetti, B.; Karsili, T. N. V.; Ashfold, M. N. R. Exploring norrish type I and type II reactions: An ab initio mechanistic study highlighting singlet-state mediated chemistry. Phys. Chem. Chem. Phys. $2019,21,14418-14428$.

(32) Schwack, W.; Rudolph, T. Photochemistry of dibenzoyl methane UVA filters Part 1. J. Photochem. Photobiol., B 1995, 28, 229-234.

(33) Roscher, N. M.; Lindemann, M. K. O.; Bin Kong, S.; Cho, C. G.; Jiang, P. Photodecomposition of several compounds commonly used as sunscreen agents. J. Photochem. Photobiol., A 1994, 80, 417421.

(34) Cantrell, A.; McGarvey, D. J. Photochemical studies of 4-tertbutyl-4'-methoxydibenzoylmethane (BM-DBM). J. Photochem. Photobiol., B 2001, 64, 117-122.

(35) Paris, C.; Lhiaubet-Vallet, V.; Jimenez, O.; Trullas, C.; Miranda, M. A. A blocked diketo form of avobenzone: Photostability, photosensitizing properties and triplet quenching by a triazine-derived UVB-filter. Photochem. Photobiol. 2009, 85, 178-184.

(36) Lhiaubet-Vallet, V.; Marin, M.; Jimenez, O.; Gorchs, O.; Trullas, C.; Miranda, M. A. Filter-filter interactions. Photostabilization, triplet quenching and reactivity with singlet oxygen. Photochem. Photobiol. Sci. 2010, 9, 552-558. 
(37) Wang, C.; Bavcon Kralj, M.; Kosmrlj, B.; Yao, J.; Kosenina, S.; Polyakova, O. V.; Artaev, V. B.; Lebedev, A. T.; Trebse, P. Stability and removal of selected avobenzone's chlorination products. Chemosphere 2017, 182, 238-244.

(38) Mturi, G. J.; Martincigh, B. S. Photostability of the sunscreening agent 4-tert-butyl-4'-methoxydibenzoylmethane (avobenzone) in solvents of different polarity and proticity. J. Photochem. Photobiol., A 2008, 200, 410-420.

(39) Vallejo, J. J.; Mesa, M.; Gallardo, C. Evaluation of the avobenzone photostability in solvents used in cosmetic formulations. Vitae-Revista De La Facultad De Quimica Farmaceutica 2011, 18, 6371.

(40) Yamaji, M.; Kida, M. Photothermal tautomerization of a uv sunscreen (4-tert-butyl-4'-methoxydibenzoylmethane) in acetonitrile studied by steady-state and laser flash photolysis. J. Phys. Chem. A 2013, 117, 1946-1951.

(41) Wong, N. G. K.; Berenbeim, J. A.; Hawkridge, M.; Matthews, E.; Dessent, C. E. H. Mapping the intrinsic absorption properties and photodegradation pathways of the protonated and deprotonated forms of the sunscreen oxybenzone. Phys. Chem. Chem. Phys. 2019, 21, 14311-14321.

(42) Wong, N. G. K.; Berenbeim, J. A.; Dessent, C. E. H. Direct observation of photochemical free radical production from the sunscreen 2-phenylbenzimidazole-5-sulfonic acid via laser-interfaced mass spectrometry. ChemPhotoChem. 2019, 3, 1231-1237.

(43) Matthews, E.; Dessent, C. E. H. Experiment and theory confirm that UV laser photodissociation spectroscopy can distinguish protomers formed via electrospray. Phys. Chem. Chem. Phys. 2017, 19, 17434-17440.

(44) Matthews, E.; Cercola, R.; Dessent, C. E. H. Protomerdependent electronic spectroscopy and photochemistry of the model flavin chromophore alloxazine. Molecules 2018, 23, 2036.

(45) Matthews, E.; Dessent, C. E. Locating the proton in nicotinamide protomers via low-resolution UV action spectroscopy of electrosprayed solutions. J. Phys. Chem. A 2016, 120, 9209-9216.

(46) Kiefer, H. V.; Gruber, E.; Langeland, J.; Kusochek, P. A.; Bochenkova, A. V.; Andersen, L. H. Intrinsic photoisomerization dynamics of protonated schiff-base retinal. Nat. Commun. 2019, 10, 1210.

(47) Saha, K.; Chandrasekaran, V.; Heber, O.; Iron, M. A.; Rappaport, M. L.; Zajfman, D. Ultraslow isomerization in photoexcited gas-phase carbon cluster $\mathrm{C}_{10}{ }^{-}$. Nat. Commun. 2018, 9, 912.

(48) Li, Y.; Qiao, X.; Zhou, C.; Zhang, Y. N.; Fu, Z.; Chen, J. Photochemical transformation of sunscreen agent benzophenone-3 and its metabolite in surface freshwater and seawater. Chemosphere 2016, 153, 494-499.

(49) De Laurentiis, E.; Minella, M.; Sarakha, M.; Marrese, A.; Minero, C.; Mailhot, G.; Brigante, M.; Vione, D. Photochemical processes involving the UV absorber benzophenone-4 (2-hydroxy-4methoxybenzophenone-5-sulphonic acid) in aqueous solution: Reaction pathways and implications for surface waters. Water Res. 2013, 47, 5943-5953.

(50) Tovar-Sanchez, A.; Sanchez-Quiles, D.; Basterretxea, G.; Benede, J. L.; Chisvert, A.; Salvador, A.; Moreno-Garrido, I.; Blasco, J. Sunscreen products as emerging pollutants to coastal waters. PLoS One 2013, 8, No. e65451.

(51) Wei, Z.; Spinney, R.; Ke, R.; Yang, Z.; Xiao, R. Effect of pH on the sonochemical degradation of organic pollutants. Environ. Chem. Lett. 2016, 14, 163-182.

(52) Thuyet, D. Q.; Watanabe, H.; Ok, J. Effect of $\mathrm{pH}$ on the degradation of imidacloprid and fipronil in paddy water. J. Pestic. Sci. 2013, 38, 223-227.

(53) Loftin, K. A.; Adams, C. D.; Meyer, M. T.; Surampalli, R. Effects of ionic strength, temperature, and $\mathrm{pH}$ on degradation of selected antibiotics. J. Environ. Qual. 2008, 37, 378-386.

(54) Barman, B. N.; Preston, H. G. The effects of $\mathrm{pH}$ on the degradation of isothiazolone biocides. Tribol. Int. 1992, 25, 281-287.

(55) Zhang, G.; Wang, Q.; Zhang, W.; Li, T.; Yuan, Y.; Wang, P. Effects of organic acids and initial solution $\mathrm{pH}$ on photocatalytic degradation of bisphenol a (BPA) in a photo-fenton-like process using goethite (alpha-feooh). Photochem. .Photobiol. Sci. 2016, 15, 10461053.

(56) Burbano, A. A.; Dionysiou, D. D.; Suidan, M. T.; Richardson, T. L. Oxidation kinetics and effect of $\mathrm{pH}$ on the degradation of MTBE with fenton reagent. Water Res. 2005, 39, 107-118.

(57) Matthews, E.; Sen, A.; Yoshikawa, N.; Bergstrom, E.; Dessent, C. E. UV laser photoactivation of hexachloroplatinate bound to individual nucleobases in vacuo as molecular level probes of a model photopharmaceutical. Phys. Chem. Chem. Phys. 2016, 18, 1514315152 .

(58) Wellman, S. M.; Jockusch, R. A. Moving in on the action: An experimental comparison of fluorescence excitation and photodissociation action spectroscopy. J. Phys. Chem. A 2015, 119, 6333-6338.

(59) Sen, A.; Luxford, T. F.; Yoshikawa, N.; Dessent, C. E. Solvent evaporation versus proton transfer in nucleobase-pt $(\mathrm{cn})(4,6)(2)(-)$ dianion clusters: A collisional excitation and electronic laser photodissociation spectroscopy study. Phys. Chem. Chem. Phys. 2014, 16, 15490-15500.

(60) Antoine, R.; Dugourd, P. Visible and ultraviolet spectroscopy of gas phase protein ions. Phys. Chem. Chem. Phys. 2011, 13, 1649416509.

(61) van Outersterp, R. E.; Martens, J.; Berden, G.; Steill, J. D.; Oomens, J.; Rijs, A. M. Structural characterization of nucleotide $5^{\prime}$ triphosphates by infrared ion spectroscopy and theoretical studies. Phys. Chem. Chem. Phys. 2018, 20, 28319-28330.

(62) Martens, J.; Berden, G.; Gebhardt, C. R.; Oomens, J. Infrared ion spectroscopy in a modified quadrupole ion trap mass spectrometer at the felix free electron laser laboratory. Rev. Sci. Instrum. 2016, 87, 103108.

(63) Oepts, D.; van der Meer, A. F. G.; van Amersfoort, P. W. The free-electron-laser user facility felix. Infrared Phys. Technol. 1995, 36, 297-308.

(64) Rijs, A. M.; Oomens, J. Ir spectroscopic techniques to study isolated biomolecules. Top. Curr. Chem. 2014, 364, 1-42.

(65) Berden, G.; Derksen, M.; Houthuijs, K. J.; Martens, J.; Oomens, $\mathrm{J}$. An automatic variable laser attenuator for IRMPD spectroscopy and analysis of power-dependence in fragmentation spectra. Int. J. Mass Spectrom. 2019, 443, 1-8.

(66) Frisch, M. J.; Trucks, G. W.; Schlegel, H. B.; Scuseria, G. E.; Robb, M. A.; Cheeseman, J. R.; Scalmani, G.; Barone, V.; Mennucci, B.; Petersson, G. A., et al. Gaussian 09, revision D.01; Gaussian, Inc.: Wallingford, CT, 2009.

(67) Schrödinger Macromodel, release 2019-4; Schrödinger, LLC: New York, NY, 2019.

(68) Rodrigues-Oliveira, A. F.; Ribeiro, F. W. M; Cervi, G.; Correra, T. C. Evaluation of common theoretical methods for predicting infrared multiphotonic dissociation vibrational spectra of intramolecular hydrogen-bonded ions. ACS Omega 2018, 3, 9075-9085.

(69) Petkovic, M.; Etinski, M. Intramolecular oho bonding in dibenzoylmethane: Symmetry and spectral manifestations. RSC Adv. 2014, 4, 38517-38526.

(70) Laurent, A. D.; Jacquemin, D. TD-DFT benchmarks: A review. Int. J. Quantum Chem. 2013, 113, 2019-2039.

(71) Demarque, D. P.; Crotti, A. E.; Vessecchi, R.; Lopes, J. L.; Lopes, N. P. Fragmentation reactions using electrospray ionization mass spectrometry: An important tool for the structural elucidation and characterization of synthetic and natural products. Nat. Prod. Rep. 2016, 33, 432-455.

(72) Debiossac, M.; Schatti, J.; Kriegleder, M.; Geyer, P.; Shayeghi, A.; Mayor, M.; Arndt, M.; Kohler, V. Tailored photocleavable peptides: Fragmentation and neutralization pathways in high vacuum. Phys. Chem. Chem. Phys. 2018, 20, 11412-11417.

(73) Gregoire, G.; Dedonder-Lardeux, C.; Jouvet, C.; Desfrancois, C.; Fayeton, J. A. Ultrafast excited state dynamics in protonated GWG and GYG tripeptides. Phys. Chem. Chem. Phys. 2007, 9, 78-82.

(74) Spezia, R.; Martinez-Nunez, E.; Vazquez, S.; Hase, W. L. Theoretical and computational studies of non-equilibrium and non- 
statistical dynamics in the gas phase, in the condensed phase and at interfaces. Philos. Trans. R. Soc., A 2017, 375, 375.

(75) Hansen, K.; Skinnerup Byskov, C.; Nielsen, S. B. Energy flow in peptides after UV photoexcitation of backbone linkages. Phys. Chem. Chem. Phys. 2017, 19, 19640-19645.

(76) Dessent, C.; Fairlamb, I.; Lynam, J.; Hammarback, A.; Wong, N.; Garand, E.; Scherman, S.; Fischer, K.; Cercola, R. Direct measurement of the visible to UV photodissociation processes for the photocorm tryptocorm. ChemRxiv 2019, https://doi.org/ 10.26434/chemrxiv.11369628.v1.

(77) Nibbering, N. M. The mclafferty rearrangement: A personal recollection. J. Am. Soc. Mass Spectrom. 2004, 15, 956-958.

(78) Dunbar, R. C.; Klein, R. Spectroscopy of radical cations. The mclafferty rearrangement product in fragmentation of n-butylbenzene and 2-phenylethanol ions. J. Am. Chem. Soc. 1977, 99, 3744-3746.

(79) Laulhe, S.; Bogdanov, B.; Johannes, L. M.; Gutierrez, O.; Harrison, J. G.; Tantillo, D. J.; Zhang, X.; Nantz, M. H. Fragmentation of oxime and silyl oxime ether odd-electron positive ions by the mclafferty rearrangement: New insights on structural factors that promote $\alpha, \beta$ fragmentation. J. Mass Spectrom. 2012, 47, 676-686.

(80) De Vijlder, T.; Valkenborg, D.; Lemiere, F.; Romijn, E. P.; Laukens, K.; Cuyckens, F. A tutorial in small molecule identification via electrospray ionization-mass spectrometry: The practical art of structural elucidation. Mass Spectrom. Rev. 2018, 37, 607-629.

(81) Filges, U.; Grützmacher, H.-F. Fragmentations of protonated acetophenones via intermediate ion-molecule complexes. Org. Mass Spectrom. 1987, 22, 444-450.

(82) Grützmacher, H.-F., Fragmentation in mass spectrometry. In Encyclopedia of spectroscopy and spectrometry; Lindon, J. C., Ed.; Elsevier: Oxford, 1999; pp 637-648.

(83) Kuck, D. From fragmentation to construction-from void to massive: Fascination with organic mass spectrometry and the synthesis of novel three-dimensional polycyclic aromatic hydrocarbons. Chem. Rec 2015, 15, 1075-1109.

(84) De Feyter, S.; Diau, E. W.; Zewail, A. H. Femtosecond dynamics of norrish type-II reactions: Nonconcerted hydrogentransfer and diradical intermediacy. Angew. Chem., Int. Ed. 2000, 39, 260-263.

(85) Douhal, A.; Lahmani, F.; Zewail, A. H. Proton-transfer reaction dynamics. Chem. Phys. 1996, 207, 477-498.

(86) Wagner, P. J. Type II photoelimination and photocyclization of ketones. Acc. Chem. Res. 1971, 4, 168-177.

(87) Bull, J. N.; Scholz, M. S.; Carrascosa, E.; Bieske, E. J. From e to $\mathrm{z}$ and back again: Reversible photoisomerisation of an isolated chargetagged azobenzene. Phys. Chem. Chem. Phys. 2018, 20, 509-513.

(88) Bull, J. N.; Carrascosa, E.; Scholz, M. S.; Coughlan, N. J. A.; Bieske, E. J. Online measurement of photoisomerisation efficiency in solution using ion mobility mass spectrometry. Analyst 2017, 142, $2100-2103$.

(89) Scholz, M. S.; Bull, J. N.; Coughlan, N. J. A.; Carrascosa, E.; Adamson, B. D.; Bieske, E. J. Photoisomerization of protonated azobenzenes in the gas phase. J. Phys. Chem. A 2017, 121, 6413-6419.

(90) Antonov, I.; Voronova, K.; Chen, M. W.; Sztaray, B.; Hemberger, P.; Bodi, A.; Osborn, D. L.; Sheps, L. To boldly look where no one has looked before: Identifying the primary photoproducts of acetylacetone. J. Phys. Chem. A 2019, 123, 5472-5490.

(91) Abid, A. R.; Marciniak, B.; Pędziński, T.; Shahid, M. Photostability and photo-sensitizing characterization of selected sunscreens' ingredients. J. Photochem. Photobiol., A 2017, 332, 241-250.

(92) Tarras-Wahlberg, N.; Stenhagen, G.; Larko, O.; Rosen, A.; Wennberg, A. M.; Wennerstrom, O. Changes in ultraviolet absorption of sunscreens after ultraviolet irradiation. J. Invest. Dermatol. 1999, $113,547-553$.

(93) Liu, Y.-S.; Ying, G.-G.; Shareef, A.; Kookana, R. S. Photostability of the uv filter benzophenone-3 and its effect on the photodegradation of benzotriazole in water. Environ. Chem. 2011, 8, 581.

(94) Serpone, N.; Salinaro, A.; Emeline, A. V.; Horikoshi, S.; Hidaka, H.; Zhao, J. An in vitro systematic spectroscopic examination of the photostabilities of a random set of commercial sunscreen lotions and their chemical UVB/UVA active agents. Photochem. Photobiol. Sci. 2002, 1, 970-981.

(95) Pandika, M. Looking to nature for new sunscreens. ACS Cent. Sci. 2018, 4, 788-790. 